\title{
REDACTIONEEL
}

\section{Omdenken over het tuchtrecht ${ }^{*}$}

\author{
Prof. mr. J. Legemaate**
}

In 2009 was ik betrokken bij een onderzoek waarin zowel klagers en aangeklaagden in het tuchtrecht werden geïnterviewd. ${ }^{1}$ Wij concludeerden onder meer dat beide partijen de tuchtrechtelijke procedure als formeel en zakelijk ervoeren. Aangeklaagden ten aanzien van wie de klacht gegrond was verklaard, bleken nadien niet zelden voor vormen van defensieve geneeskunde te hebben gekozen. Klagers rapporteerden dat de tuchtprocedure een vervreemdende werking had, ook al omdat aan persoonlijk contact met de zorgverlener door het indienen van een tuchtklacht veelal een einde kwam. Wij hadden als onderzoekers niet de indruk dat dit alles bijdroeg aan verbetering van de kwaliteit van zorg. Ik moest daar weer aan denken toen ik onlangs een recente publicatie van Laarman e.a. las. Zij legden een vragenlijst voor aan artsen die tussen 2012 en 2016 van de tuchtrechter een waarschuwing of een berisping kregen. ${ }^{2}$ De focus van hun artikel is een wat andere dan die van ons eerdere onderzoek, maar ik kwam toch veel vergelijkbare bevindingen tegen. Een groot aantal respondenten rapporteert een negatieve impact van de tuchtprocedure op hun medische praktijk. Een behoorlijk aantal van hen doet vaker aan defensieve geneeskunde, probeert lastige patiënten te vermijden en ziet elke patiënt als een potentiële nieuwe klager. Dat zij na de tuchtprocedure ook vaker met collega's spreken over verbetermaatregelen en proberen beter met patiënten te communiceren, weegt daar maar in beperkte mate tegenop. De auteurs concluderen zuinigjes dat het tuchtrecht 'both positive and negative effects on professional practice' heeft. Optimaal is het allemaal niet, bezien vanuit de op kwaliteitsverbetering gerichte doelstelling van het tuchtrecht.

Het zullen dergelijke bevindingen zijn geweest die aanleiding gaven tot de kritiek op het tuchtrecht die de Raad voor Volksgezondheid \& Samenleving (RVS) in 2019 formuleerde. In een rapport over de toekomstbestendigheid van de Wet BIG lezen we onder meer het volgende: 'Het tuchtrecht zou meer dan nu gericht moeten zijn op kwaliteitsbevordering; zorgverleners moeten kunnen leren en verbeteren, zowel op individueel als op collectief niveau (...). Daarnaast is het wenselijk dat het tuchtrecht minder als een openbare terecht-

* $\quad$ Deze bijdrage geeft de persoonlijke opvattingen van de auteur weer.

** Johan Legemaate is hoogleraar gezondheidsrecht AUMC/UvA, lid-jurist in het Centraal Tuchtcollege voor de Gezondheidszorg en redacteur van dit tijdschrift.

1 Y. Alhafaji, B. Frederiks \& J. Legemaate, 'Ervaringen van klagers en aangeklaagde artsen met het tuchtrecht', Nederlands-Vlaams Tijdschrift voor Mediation en Conflictmanagement 2009, nr. 3, p. 18-42.

2 B.S. Laarman, R.J.R. Bouwman, A.J.E. de Veer \& R.D. Friele, 'Is the perceived impact of disciplinary procedures on medical doctors' professional practice associated with working in an open culture and feeling supported? A questionnaire among medical doctors in the Netherlands who have been disciplined', BMJ Open 2020

(DOI: 10.1136/bmjopen-2020-036922). 
stelling van individuele zorgverleners fungeert.' Die laatste zinsnede leidt tot het voorstel om in het tuchtrecht weer het uitgangspunt 'geen openbaarheid, tenzij' te gaan hanteren. Begin 2020 stelde de Minister van VWS een stuurgroep in, bestaande uit vertegenwoordigers van branche- en koepelorganisaties in de zorg, die zich in het verlengde van het RVSadvies boog over de toekomst van de Wet BIG. Waar het gaat over het tuchtrecht sloot de stuurgroep zich min of meer bij de RVS aan: in aanvulling op de corrigerende werking zou het tuchtrecht meer gericht moeten zijn op het leren en verbeteren door zorgverleners. In november 2020 liet de minister de Tweede Kamer weten dat 'de komende tijd bekeken [zal] worden hoe dit het beste bewerkstelligd kan worden'. ${ }^{4} \mathrm{Ik}$ ben benieuwd.

Als lid-jurist van het CTG maak ik het tuchtrecht van nabij mee. Dat het tuchtrecht ook in zijn huidige vorm nuttig is, staat voor mij buiten kijf. Dat blijkt alleen al uit de normerende en rechtsvormende werking van tuchtuitspraken. En in een aantal gevallen is het opleggen van een individuele tuchtrechtelijke maatregel nodig en rechtvaardig. Maar ik zie ook de nadelen. Die liggen deels in de sfeer van de resultaten van de beide onderzoeken die ik hiervoor noemde, maar hebben ook te maken met het wisselende belang van ingediende klachten voor de kwaliteit van zorg. Daarnaast bemoeilijkt de sterke focus van het tuchtrecht op individuele verantwoordelijkheid het aanpakken van kwaliteitsproblemen binnen een team of een netwerk.

Het 'tucht'-recht heeft zijn naam natuurlijk ook niet mee. En de setting waarin het openbare deel van de procedure zich afspeelt, de eerder tot confrontatie dan tot harmonie aanleiding gevende zittingszaal van het Paleis van Justitie, helpt ook niet altijd. Die hele context werkt in veel gevallen eerder belemmerend dan stimulerend op leren en verbeteren door de betreffende beroepsbeoefenaar of binnen de beroepsgroep. Ik denk af en toe best wel eens: zouden we een 'tucht'-zaak niet beter kunnen beginnen met een goed gesprek, aan een ronde tafel en 'gelijkvloers' en met een breed scala van mogelijke opties (zoals de mogelijkheid van een overeen te komen verbeterplan)? En zou het college niet ook de mogelijkheid moeten hebben beide partijen eens een uurtje de gang op te sturen, om te kijken of ze er (toch) samen uit kunnen komen? Opschalen naar een meer formeel niveau, vanwege de gebleken noodzaak tot het corrigeren van de beroepsbeoefenaar, kan dan een tweede fase zijn. Dat zou dan ook de fase kunnen zijn die openbaar is.

Nadenken over mogelijkheden voor een veel betere 'alignment' tussen het tuchtrecht en het voor de kwaliteit van de zorg zo belangrijke domein van leren en verbeteren is zeker de moeite waard. Out of the box.

3 Raad voor Volksgezondheid \& Samenleving, De B van Bekwaam - Naar een toekomstbestendige Wet BIG, Den Haag, 2019, p. 55-56. Dit rapport is door Gevers besproken in TvGR 2020, p. 342-350, maar hij laat het thema tuchtrecht buiten beschouwing.

4 Kamerstukken II 2020/21, 29282, nr. 415. 